\title{
Activation of the infralimbic cortex in a fear context enhances extinction learning
}

\author{
Brittany M. Thompson, ${ }^{1,4}$ Michael V. Baratta, ${ }^{2}$ Joseph C. Biedenkapp, ${ }^{3}$ Jerry W. Rudy, ${ }^{1}$ \\ Linda R. Watkins, ${ }^{1}$ and Steven F. Maier ${ }^{1}$ \\ ${ }^{1}$ Department of Psychology and Neuroscience, University of Colorado, Boulder, Colorado 80309-0345, USA; ${ }^{2}$ MIT Media Laboratory \\ and the Department of Brain and Cognitive Sciences, Cambridge, Massachusetts, 02139-4307, USA; ${ }^{3}$ Picower Institute for Learning \\ and Memory, Massachusetts Institute of Technology, Cambridge, Massachusetts 02139, USA
}

\begin{abstract}
Activation of the infralimbic region (IL) of the medial prefrontal cortex (mPFC) reduces conditioned fear in a variety of situations, and the IL is thought to play an important role in the extinction of conditioned fear. Here we report a series of experiments using contextual fear conditioning in which the IL is activated with the GABAa antagonist picrotoxin (Ptx) during a single extinction session in the fear context. We investigate the impact of this manipulation on subsequent extinction sessions in which Ptx is no longer present. First, we demonstrate that a single treatment with intra-IL Ptx administered in a conditioned fear context greatly accelerates the rate of extinction on the following days. Importantly, IL-Ptx also enhances extinction to a different fear context than the one in which IL-Ptx was administered. Thus, IL-Ptx primes extinction learning regardless of the fear context in which the IL was initially activated. Second, activation of the IL must occur in conjunction with a fear context in order to enhance extinction; the extinction enhancing effect is not observable if IL-Ptx is administered in a neutral context. Finally, this extinction enhancing effect is specific to the IL for it does not occur if Ptx is injected into the prelimbic region (PL) of the mPFC. The results indicate a novel persisting control of fear induced by activation of the IL and suggest that IL activation induces changes in extinction-related circuitry that prime extinction learning.
\end{abstract}

The extinction of fear is an important adaptive process in which the organism learns to suppress responding to a stimulus associated with fear. Extinction of a conditioned response typically occurs when the conditioned stimulus (CS) is repeatedly presented in the absence of an aversive consequence (unconditioned stimulus [US]). It is generally believed that the extinction process does not erase the fear memory; rather, extinction is thought to result in new learning that inhibits the conditioned fear (for review, see Bouton 2004; Myers and Davis 2007). Thus, extinction depends on active suppression of the conditioned fear response, likely by inhibiting output of the central nucleus of the amygdala (CeA) (Amano et al. 2010), as the CeA is thought to be the final integrative region controlling fear responses (for review, see Fendt and Fanselow 1999; Maren and Quirk 2004; Paré et al. 2004; Ehrlich et al. 2009).

Several lines of evidence have implicated the medial prefrontal cortex (mPFC) as a critical substrate in extinction processes and the suppression of fear, and the mPFC is heavily interconnected with the amygdala. In particular, activation of the infralimbic (IL) region of the mPFC decreases CeA output (Quirk et al. 2003). This effect of the IL is thought to be executed through IL projections that densely innervate clusters of GABAergic cells of the amygdala that are interspersed between the borders of the basolateral amygdala (BLA) and CeA referred to as intercalated cells (ITC) (Cassel and Wright 1986; McDonald et al. 1996; Vertes 2004; Likhtik et al. 2005; Pinto and Sesack 2008). These ITC cells exert feed-forward inhibition on the CeA (Royer et al. 1999; Paré et al. 2003) and may be important for extinction (Likhtik et al. 2008). Consistent with the functional anatomy of the IL, the literature reveals that manipulations that impair or

${ }^{4}$ Corresponding author.

E-mail brittany.m.thompson@colorado.edu; fax (303) 492-2967.

Article is online at http://www.learnmem.org/cgi/doi/10.1101/lm.1920810. stimulate the IL can impair (Hugues et al. 2004; Burgos-Robles et al. 2007; Mueller et al. 2008; Laurent and Westbrook 2009; Sotres-Bayon et al. 2009) or enhance extinction accordingly (Milad and Quirk 2002; Milad et al. 2004; Vidal-Gonzalez et al. 2006).

Moreover, activation of the IL can alter the impact of a subsequent encounter with an aversive event such as stress. Our laboratory has generated evidence that the IL and prelimbic regions $(\mathrm{PL})$ of the mPFC are activated during controllable stress (Baratta et al. 2009). Activation of the mPFC either behaviorally (with control over the stressor) or pharmacologically during an uncontrollable stressor (with the GABAa antagonist picrotoxin [Ptx]) can regulate the neurochemical and behavioral responses to that stressor (Amat et al. 2005). This activation of the mPFC during aversive experiences alters the impact of future challenges, indicating that the mPFC guides the neural and behavioral response to subsequent challenges (Amat et al. 2006, 2008; Maier et al. 2006). For example, mPFC activation with controllable stress reduces the expression of conditioned fear (Baratta et al. 2007, 2008). These data lead us to believe that mPFC activation during an aversive event can induce neural changes that alter the effect of future aversive events.

The experiments we report here were designed to evaluate whether IL activation in an aversive context might have longterm effects on the regulation of fear. Specifically, we activated the IL during a single extinction session and we examined the effect of this manipulation on subsequent fear extinction trials during which artificial IL activation is no longer present. We envisioned at least two potential ways that IL activation could exert its effects on subsequent extinction. This experience could (1) enhance the ability of these neurons to control the expression of the freezing during subsequent extinction sessions; or (2) output from these activated neurons during the first extinction might in someway enhance subsequent learning by modulating the 
ability to induce plasticity needed for the new learning (Amano et al. 2010). It should be clearly noted that the question posed is not whether IL activation reduces the expression of fear or whether the IL is involved in extinction as has been repeatedly shown (Milad and Quirk 2002; Milad et al. 2004; Vidal-Gonzalez et al. 2006). Rather, the issue is whether activating the IL during the experience of conditioned fear might facilitate subsequent fear extinction during which artificial IL activation is no longer present. In the series of experiments presented here, rats were given a strong fear conditioning experience followed the next day by IL activation during a brief (5-min) extinction session. The IL was selectively activated in a fear context by microinjecting Ptx, which activates pyramidal output cells of the IL (ChagnacAmitai and Connors 1989). It has already been shown that intra-IL-Ptx induces the expression of the immediate early gene c-Fos in ITC cells (Berretta et al. 2005). The effects of IL-Ptx on conditioned freezing were observed during brief extinction sessions over several days following that single injection. The results indicate a novel persisting control of the fear by the IL.

\section{Results}

\section{Cannula placement}

Only animals with cannulae terminating in the IL (or PL for Experiment 5) were included for data analysis. Representative cannulae placements for Experiments 1, 2, 3, 4, and 6, as indicated by the site of Evans Blue, are shown in Figure 1 (left). PL cannulae placements for Experiment 5 are shown in Figure 1 (right). reliable until Day 3. This suggests that IL activation might enhance the new learning that supports extinction.

\section{Experiment 2: IL-Ptx enhances extinction learning}

It is clear that IL-Ptx accelerates extinction; however, this effect was not observed during the first extinction session the day following IL-Ptx. In the previous experiment, the extinction sessions were relatively brief ( $5 \mathrm{~min}$ ) and may not have been long enough to reveal an effect of previous IL-Ptx. Thus, in Experiment 2 rats $(n=9)$ received an extended (20-min) extinction session in order to determine if the Ptx can facilitate extinction learning (Fig. 3A). As expected, on Day 1 IL-Ptx reduced freezing $\left(t_{(16)}=2.75, P<0.05\right)$. Of greater interest, this treatment greatly accelerated the rate of extinction on Day 2 (Fig. 3B). A repeated-measures ANOVA with a Greenhouse-Geisser correction on Day 2 freezing data revealed a significant main effect of drug $\left(F_{(1,16)}=10.56, P<0.01\right)$, a significant main effect of time $\left(F_{(1.36,21.69)}=18.67, P<0.001\right)$, and a significant drug $\times$ time interaction $\left(F_{(1.36,21.69)}=4.83, P<0.05\right)$.

Therefore, IL-Ptx greatly accelerates the rate of extinction, and this effect requires extended extinction learning before it is observable. These data suggest that treatment with IL-Ptx primes the mechanisms that support extinction.

\section{Experiment 3: The effects of IL-Ptx transfer between fear contexts}

It is clear that IL-Ptx in a fear context accelerates extinction. This finding suggests that the activation of the IL during the first extinction session influences the subsequent regulation of fear. The purpose of Experiment 3 was to determine if the effect of IL-Ptx is specific to the context in which it was administered.

\section{Experiment 1: IL activation in a fear context enhances fear extinction}

The goal of Experiment 1 was to determine the effects of IL activation on subsequent fear extinction. Rats $(n=6)$ received contextual fear conditioning on Day 0. On Day 1 they received IL-Ptx or Sal prior to being tested in the conditioned context. On Days 2, 3, and 4, the same animals were tested in the conditioned context without a drug injection (see Fig. 2A for experimental design). It is clear that Ptx markedly reduced freezing on the injection day $\left(t_{(10)}=3.199\right.$, $P<0.01)$. There was no effect of Ptx on the first extinction day after the Ptx injection (Day 2). However, prior IL-Ptx greatly reduced freezing on extinction Days 3 and 4 (Fig. 2B). A repeated-measures analysis of variance (ANOVA) revealed a significant main effect of day $\left(F_{(2,20)}=6.22, P<0.01\right)$ and significant main effect of drug $\left(F_{(1,10)}=6.50, P<\right.$ $0.05)$ such that animals treated with ILPtx on Day 1 displayed reduced fear. Post-hoc pairwise analyses revealed that Ptx group freezing was significantly lower than Sal on Days 3 and 4.

Thus, IL-Ptx on Day 1 significantly reduced conditioned freezing on Day 1 and had the enduring effect of reducing freezing on subsequent days even though Ptx was no longer present. It is important to note that the effect of IL-Ptx on Days 2 through 4 was not statistically

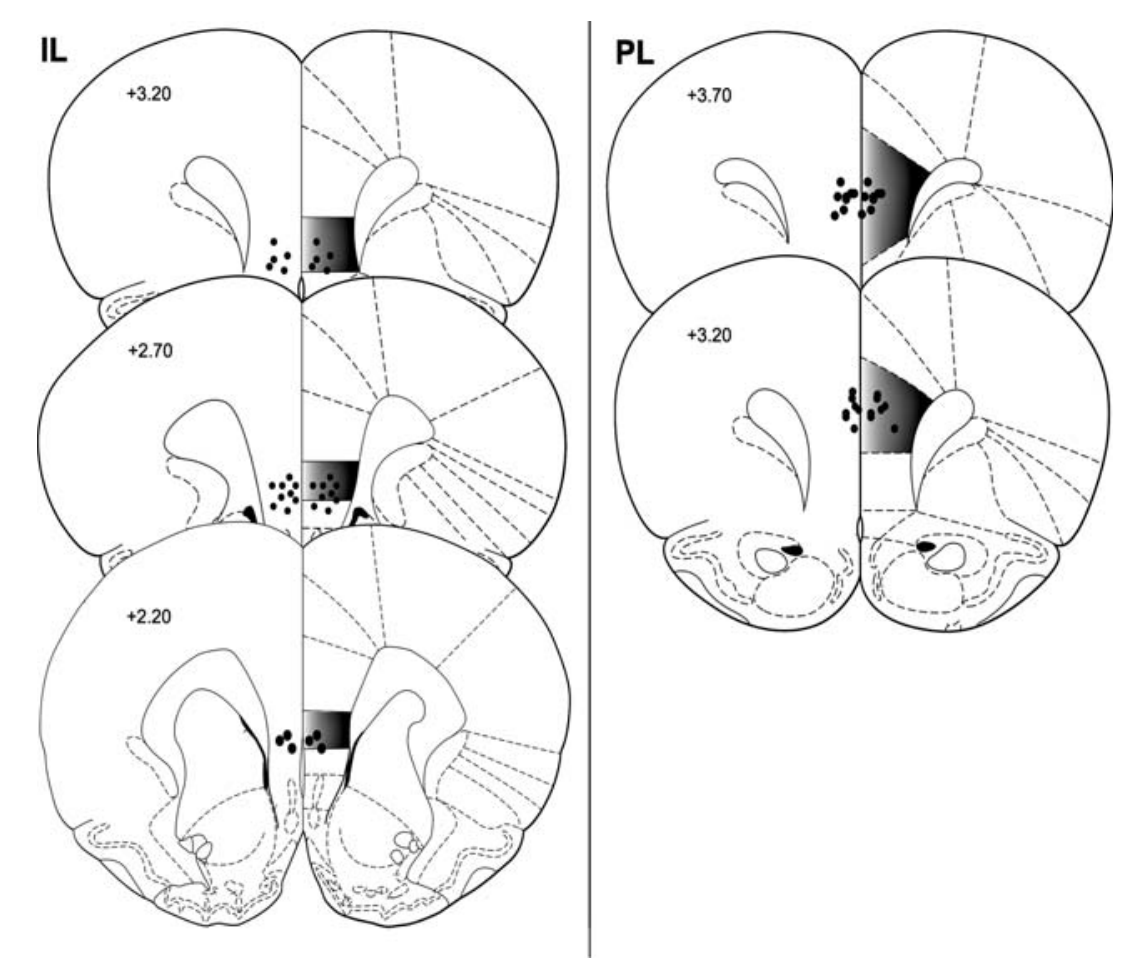

Figure 1. Site of injections in the IL (Experiments 1, 2, 3, 4, and 6) and PL (Experiment 5). Circles represent injector tip placements that are representative of rats in all experiments. Numbers indicate distance from bregma (millimeters). (Figure adapted from Paxinos and Watson [1998] and reprinted with permission from Elsevier (C) 1998.) 


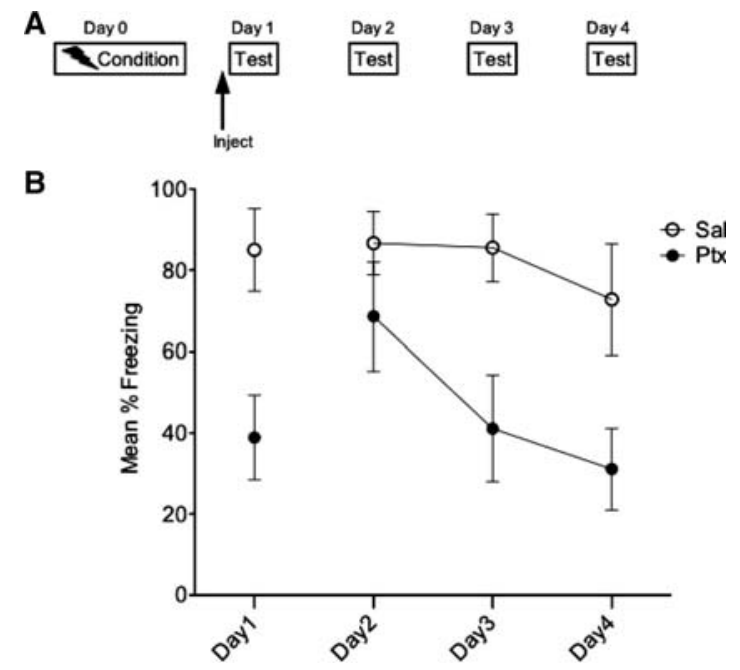

Figure 2. Experiment 1. Experimental design $(A)$ and mean percent total time spent freezing (B). IL-Ptx reduced freezing in a conditioned context (Day 1) and this single activation enhanced the rate of extinction (Days 2 through 4). Bars, SE.

In Experiment 3, rats $(n=16)$ were first conditioned to two contexts: Context A and B. On Day 1 rats received IL-Ptx or Sal prior to being tested in Context A. On the following days (Days 2 through 7) animals received extinction sessions in the opposite conditioned context, Context $\mathrm{B}$ (note the specific features of $\mathrm{A}$ and B were counterbalanced; Fig. 4A).

There was no statistical difference in freezing based on context so the data was collapsed across contexts. As expected, on Day 1 IL-Ptx reduced freezing $\left(t_{(32)}=5.847, P<0.0001\right)$. Of greater interest, these animals did not differ from controls on Day 2. However, they showed a significantly accelerated rate of extinction on the following days (Fig. 4B). A repeated-measures ANOVA with a Greenhouse-Geisser correction revealed a significant main effect of day $\left(F_{(3.66,117.19)}=50.112, P<0.0001\right)$, a significant main effect of drug $\left(F_{(1,32)}=17.52, P<0.0001\right)$, and a significant day $\times$ drug interaction $\left(F_{(3.66,117.19)}=2.93, P<0.05\right)$.

The above results imply that the effect of IL-Ptx is not specific to the context in which it was administered. Moreover, these results indicate that IL-Ptx facilitates the acquisition of extinction rather than altering a process that regulates the expression of fear. This conclusion receives additional support from the third phase of the experiment described next.

In this phase, the rats were given three additional extinction sessions on Days 8, 9, and 10, now in the context (A) where they had originally received the drug on Day 1 . There was no generalization of extinction on the first session (Day 8). However, rats that had received IL-Ptx extinguished more rapidly than Sal-treated rats on the following days. A repeated-measures ANOVA using mixed models to account for data with missing values was used. Analysis revealed a significant main effect of drug $\left(F_{(1,37.37)}=4.40, P<0.05\right)$, a significant main effect of day $\left(F_{(1,37.37)}=186.96, \quad P<0.001\right)$, and a significant day $\times$ drug interaction $\left(F_{(2,21.80)}=6.96, P<0.01\right)$. Post-hoc analysis indicated that the groups did not differ on Day 8 but did differ on Days 9 and 10.

The conclusion from these data is that IL-Ptx altered the rate of extinction for the fear response. This was true for both the extinction sessions in Context $\mathrm{B}$ and extinction sessions in Context A, suggesting that IL-Ptx treatment altered the mechanisms that support new learning produced by extinction training.
Experiment 4: IL activation needs to occur in a fear context to produce the enhanced extinction effect

The general hypothesis is that it is IL-Ptx in conjunction with the elicited fear that is needed to produce the outcome of accelerated extinction. Experiment 4 was designed to test this hypothesis. Additionally, Experiment 4 controlled for any nonspecific effects on freezing of the Ptx injection. On Day 0 , all rats $(n=9)$ were exposed to two contexts (A and B) but only shocked in A. On Day 1, rats received IL-Ptx or Sal and were placed in either the fear context or neutral context (A or B, respectively). On Days 2, 3 , and 4 , all animals were tested only in the fear context, A (see Fig. 5A).

On the injection day animals in the neutral context (B) displayed very little freezing. Animals in the fear context (A) displayed high freezing and IL-Ptx significantly reduced the freezing to Ctx A compared with Sal controls (Fig. 5B). A 2 (context) $\times 2$ (drug) ANOVA on Day 1 freezing revealed a highly significant main effect of drug $\left(F_{(1,29)}=15.654, P<0.0001\right)$, a highly significant main effect of context $\left(F_{(1,29)}=61.396, P<\right.$ $0.0001)$, and a highly significant interaction of drug $\times$ context $\left(F_{(1,29)}=13.867, P<0.001\right)$ such that freezing differed based on drug and the context in which it was administered.

Of more importance, the group that received the combination of IL-Ptx in the fear context was the only group to display accelerated extinction on the following days. IL-Ptx in a neutral context did not significantly affect freezing compared with Sal controls (Fig. 5B). A $2 \times 2$ repeated-measures ANOVA on Days 2 through 4 revealed a significant main effect of drug $\left(F_{(1,29)}=\right.$ 13.139, $P<0.001)$, a significant main effect of day $\left(F_{(2,58)}=\right.$ 25.871, $P<0.0001)$, and a significant main effect of context $\left(F_{(1,29)}=7.178, P<0.01\right)$. The day $\times$ drug interaction was very close to reaching significance $\left(F_{(2,58)}=3.132, P=0.051\right)$. Posthoc pairwise comparisons revealed that Ptx-A animals froze significantly less than did the other groups on Days 3 and 4 .

These results replicate the observations made in Experiment 1. More importantly, Experiment 4 indicates that the activation of the IL in a fear context is crucial for the persisting effects of IL

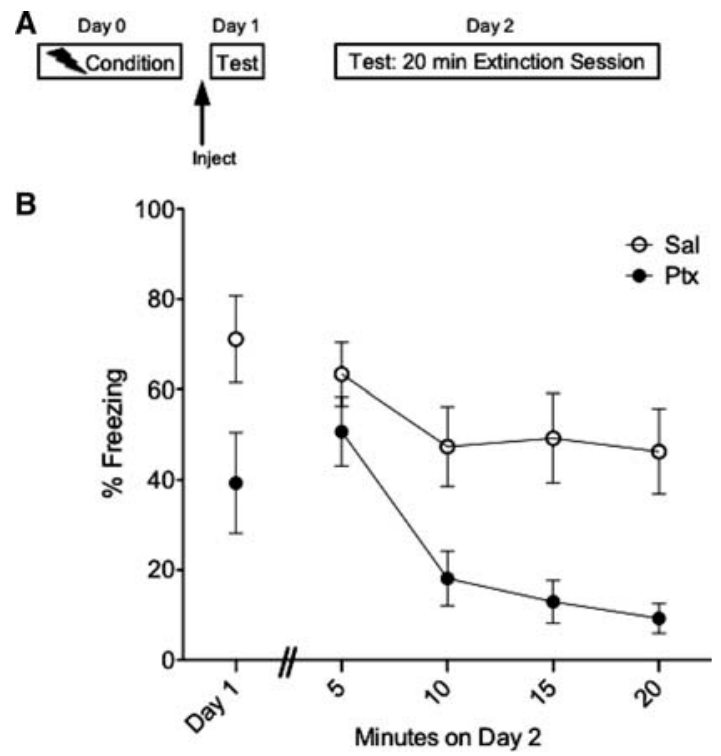

Figure 3. Experiment 2. Experimental design $(A)$ and mean percent total time spent freezing $(B)$. Acute IL-Ptx on Day 1 reduced freezing in the conditioned context. This treatment enhanced the rate of extinction during a long extinction session on Day 2. Bars, SE. 


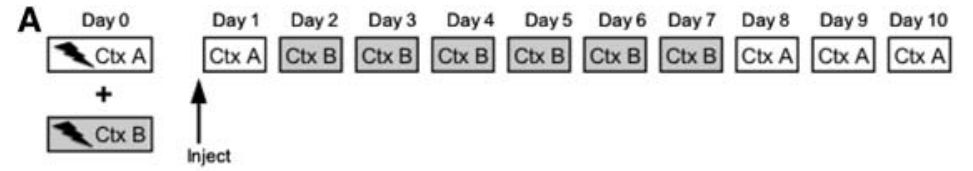

B

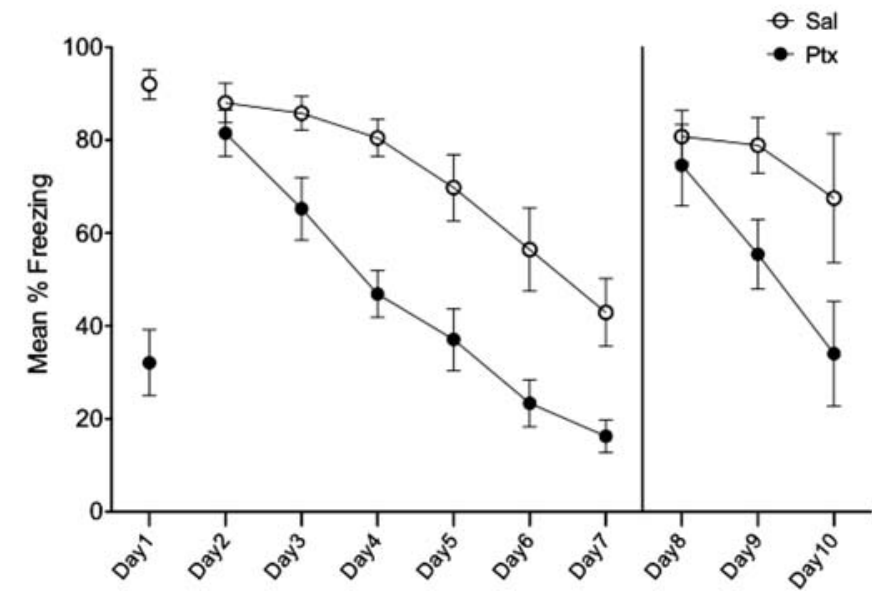

Figure 4. Experiment 3. Experimental design $(A)$ and mean percent total time spent freezing $(B)$. Animals received conditioning in two different contexts. Acute IL-Ptx in Context A reduced freezing on Day 1, and this treatment resulted in enhanced extinction learning in Context B on Days 2-7. On Days 8-10, animals tested in the injection context (A) also showed enhanced extinction learning. These results indicate that IL-Ptx enhances extinction learning across contexts. Bars, SE.

activation. Additionally, these results demonstrated that Ptx, as a pharmacological agent alone, does not account for the reduction in freezing observed over several days.

\section{Experiment 5: The enhanced extinction effect is specific to IL activation; PL activation fails to enhance extinction}

The goal of Experiment 5 was to determine whether the IL is the critical region mediating the effects observed in the preceding experiments. To do this, we repeated Experiment 1 but microinjected into the PL instead ( $n=7$; see Fig. $6 \mathrm{~A}$ ). This region was chosen because it is located close to the IL but projects to different regions (Vertes 2004). As shown in Figure 6B, rats injected with Ptx displayed reduced freezing on the injection day $\left(t_{(12)}=4.04, P<\right.$ 0.01 ) but did not differ from vehicle injected rats on Days 2-8. The repeated-measures ANOVA on Days 2-8 did find a significant main effect of day $\left(F_{(6,72)}=17.175, P<0.0001\right)$ such that freezing decreased over time regardless of drug group.

Thus, the enduring effect on freezing produced by IL activation is specific to the IL; these effects were not observed with PL-Ptx because PL-Ptx failed to accelerate extinction on subsequent days.

\section{Experiment 6: The changes initiated by IL-Ptx are temporally limited}

The final experiment was designed to determine whether the effect of IL-Ptx has a time limit. To address this question, we repeated the basic experiment but the extinction sessions were delayed by 6 -d post-injection ( $n=9$; Fig. 7A). On Days 8 through 10 animals were tested in the conditioned context. IL-Ptx reliably reduced freezing on Day $1\left(t_{(16)}=3.902, P<0.001\right)$. However, this treatment had no significant effect on subsequent extinction sessions. A repeated-measures ANOVA revealed that neither the main drug effect nor the drug $\times$ day interaction were significant. However, the main effect of day reached significance $\left(F_{(2,32)}=\right.$ 22.701, $P<0.0001)$.
These data indicate that the changes initiated by Ptx activation of the IL in the fear context is temporally limited and are absent by 1 wk post-injection.

\section{Discussion}

The experiments reported here were motivated by the idea that activating the IL during a fearful experience might alter the expression of fear beyond that experience. Accordingly, the IL was activated with the GABAa antagonist Ptx while the subjects were in a fearconditioned context. We choose to call this an extinction session because the CS (fear context) was presented but not reinforced with a shock. However, this brief extinction session was not sufficient to produce an observable reduction in freezing, and some might call it a fear reactivation session. The expression of fear during the artificial IL stimulation (Day 1) and on subsequent days was measured. The experiments revealed that IL-Ptx in a conditioned context both reduced freezing during Ptx administration and enhanced extinction on subsequent days when the drug was no longer present. This effect was dependent on the IL being activated in a fear context; IL activation in a neutral context had no effect on subsequent fear expression. Moreover, this effect was specific to the IL; Ptx in the PL did not produce the same effect on extinction. These data support the general conclusions that IL activation in a fear context primes the learning mechanisms that support extinction. These data are not the first to show that IL stimulation reduces freezing and enhances extinction (Milad and Quirk 2002; Milad et al. 2004; Vidal-Gonzalez et al. 2006). Electrical stimulation of the IL does indeed impair CeA excitation (Quirk et al. 2003) and reduces freezing to a conditioned tone (Milad and Quirk 2002). However, we wish to focus our discussion on the more interesting finding that IL activation produces substantial enhancements in extinction that develop even after the artificial stimulation is no longer present.

\section{IL activation and metaplasticity}

These experiments revealed that an intra-IL injection of Ptx greatly accelerates the rate of extinction on subsequent days. It is important to note, however, that the effect was not evident on the extinction session the following day. These results suggest that IL-Ptx primes the extinction circuitry in a way that allows extinction to be acquired at an enhanced rate. The priming of extinction learning by IL-Ptx might be viewed as metaplasticity effects. Metaplasticity is defined as the "plasticity of plasticity" (Abraham and Bear 1996; Abraham 1999, 2008), and this term refers to an alteration in the state of a neuron that changes the threshold at which plasticity may be induced and subsequently supports learning-related changes. Generally speaking, the concept recognizes that "the history of synaptic activity is an additional variable that influences the synaptic state" (Abraham 1999). We present two points that support metaplasticity as mediating the effects of IL-Ptx.

First, the effect of IL-Ptx did not manifest itself immediately; rather, the enhancements in extinction required at least one extinction session following Ptx infusion (or an extensive 

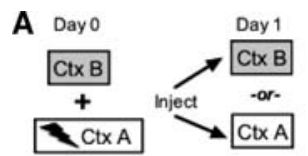

B

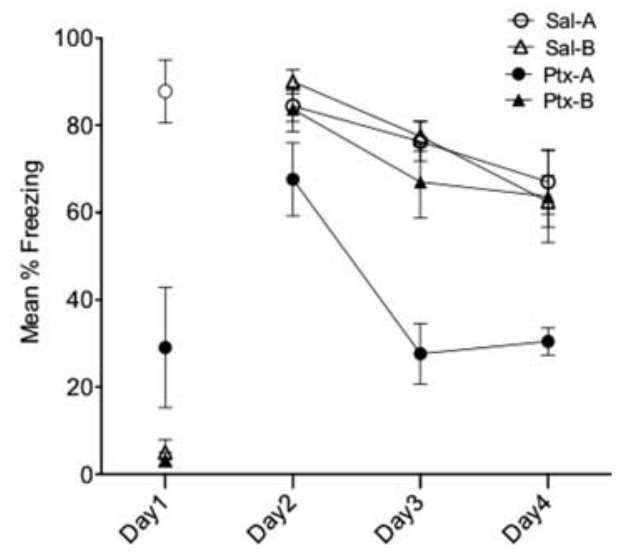

Figure 5. Experiment 4. Experimental design $(A)$ and mean percent total time spent freezing $(B)$. Animals were exposed to Context $A$ and $B$ but only shocked in A. IL-Ptx administered in the neutral context (B) did not produce enhanced extinction in Context $A$, indicating the fear context is necessary in conjunction with IL activation to produce accelerated extinction. Bars, SE.

extinction session). This suggests that IL-Ptx does not immediately induce learning or alter the fear memory but that it enhances subsequent learning. Second, the effect of IL-Ptx was not context specific. Experiment 3 revealed that IL-Ptx in one fear context, A, enhanced the rate of extinction to another fear context, B. This result reinforces the previous conclusion that the effect of Ptx did not simply enhance extinction to the context present during the administration of Ptx. In addition, it suggests that the IL-Ptx alters the properties of the neurons that support extinction learning. That is, IL activation might induce metaplastic changes in the areas involved in extinction that, in turn, accelerate extinction learning.

We propose at least two possible sites of metaplastic changes induced by IL-Ptx. One possibility is that the activation of IL circuitry by Ptx might in some way make the neurons in this region more responsive to subsequent extinction training sessions and thus amplify the contributions of the IL to extinction. This possibility is consistent with the literature indicating that the IL contributes to the extinction process. Various manipulations that impair IL activity during extinction training impair the recall of extinction on the following day (Hugues et al. 2004; Burgos-Robles et al. 2007; Mueller et al. 2008; Laurent and Westbrook 2009; Sotres-Bayon et al. 2009, but see Chang and Maren 2010). In fact, a lack of IL activity during extinction training may be responsible for extinction deficits (Kim et al. 2010). There is also evidence that the IL is activated by extinction training as extinction induces several activity and plasticity markers within the IL (Herry and Mons 2004; Santini et al. 2004, 2008; Bredy et al. 2007; Knapska and Maren 2009; Mamiya et al. 2009) and the IL displays a sustained pattern of spontaneous activity up to $2 \mathrm{~h}$ following extinction (BurgosRobles et al. 2007). Interestingly, the success of extinction recall is directly correlated with the amount of IL activity post-extinction training (Gonzalez-Lima and Bruchey 2004; Burgos-Robles et al. 2007). Thus, it is possible that activating the IL with Ptx enhances the future contribution of this system to the extinction process.
A second possibility is that the activation of the IL with Ptx induces a downstream metaplastic effect on "extinction" neurons in the BLA (Herry et al. 2008) or inhibitory ITC cells (Amano et al. 2010). Both receive input from the IL (Brinley-Reed et al. 1995; McDonald et al. 1996; Smith et al. 2000; Vertes 2004; Gabbott et al. 2005; Pinto and Sesack 2008) and display activity-dependent plasticity that can support extinction (Royer and Paré 2002; Herry et al. 2008; Laurent and Westbrook 2008; Ehrlich et al. 2009; Amano et al. 2010). The IL input to ITC cells seems to be particularly important for extinction, and ITC cell clusters are important in inhibiting the CeA output (Royer et al. 1999; Paré et al. 2003). Moreover, IL input is required for extinction-related changes in ITC cells (Amano et al. 2010). Given this evidence, it is reasonable to speculate that the high amount of IL activity onto ITC neurons generated by Ptx could alter the subsequent ability of ITC cells to be modified by extinction.

\section{Fear in conjunction with IL activation is necessary for the accelerated extinction effect}

Experiment 4 revealed that IL-Ptx administration in a neutral context is not sufficient to induce persisting changes in the expression of fear. Peters et al. (2010) have reported seemingly similar effects such that the infusion of BDNF into the IL enhances extinction; this facilitation does not occur if BDNF is infused prior to fear conditioning. However, according to Peters et al. (2010), an infusion of BDNF into the IL does not require extinction training to be observed. Our results are unique in this regard: IL-Ptx alone does not substitute for extinction training and IL-Ptx must be administered in the fear context in order to observe an effect on extinction. This experiment does not allow determination of the specific components of the fear context that are crucial during IL-Ptx for the enhancements in extinction on subsequent days; however, it is clear that emotionally arousing experiences gain a salient status in memory. The BLA is necessary for extinction (Laurent and Westbrook 2008; Laurent et al. 2008) and extinction involves enhanced ITC cell responsivity to BLA inputs (Amano et al. 2010). In the experiments presented here, activation of the BLA within the fear context might be necessary during IL activation to produce the accelerated extinction. Thus, the changes

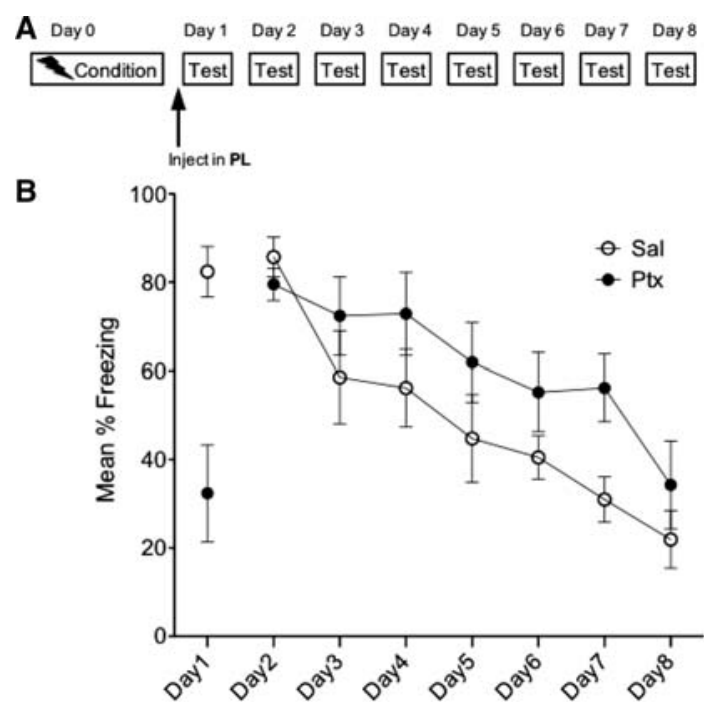

Figure 6. Experiment 5. Experimental design $(A)$ and mean percent total time spent freezing $(B)$. Acute PL-Ptx reduced freezing in a conditioned context on Day 1. Ptx treatment on Day 1 did not significantly alter the expression of fear on subsequent days (Days $2-8$ ). Bars, SE. 


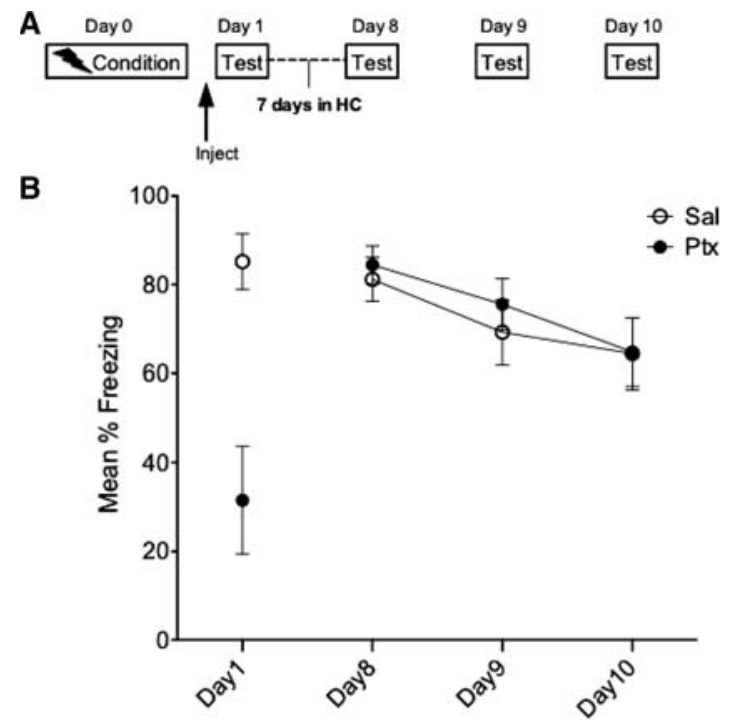

Figure 7. Experiment 6. Experimental design $(A)$ and mean percent total time spent freezing $(B)$. When IL-Ptx in the conditioned context is separated by $6 \mathrm{~d}$ from additional testing in the conditioned context, Ptx treatment fails to reduce freezing on Days 8-10. Thus, the changes initiated by Ptx on Day 1 are transient. Bars, SE.

produced by IL-Ptx that enhance extinction might require converging input from both the IL and the BLA. Moreover, exposure to a conditioned fear cue or context increases a combination of molecules that are typically released during salient experiences. For example, exposure to a conditioned context elevates peripheral glucocorticoids, and mPFC extracellular dopamine, acetylcholine, and noradrenaline (Wedzony et al. 1996; Feenstra et al. 2001; Hugues et al. 2007). Any one of these, alone or in addition to other neurotransmitters/modulators, could act to enhance cellular signaling and strengthen synapses ( $\mathrm{Gu}$ 2002). The element(s) necessary for the changes that accompany IL activation is yet to be identified; however, it is clear that the effects observed are not pharmacological artifacts of Ptx injection.

\section{PL activation acutely reduces freezing but does not accelerate extinction}

The reduction of freezing by acute PL-Ptx on Day 1 in Experiment 5 was surprising because the afferent projections of the PL differ from those of the IL. In particular, neurons from the PL do not synapse on ITC cells of the amygdala. Rather, PL projections are thought to synapse primarily on pyramidal spines in the BLA (Brinley-Reed et al. 1995; Vertes 2004) and PL stimulation drives the BLA (McDonald et al. 1996; Likhtik et al. 2005; but see Rosenkranz and Grace 2001, 2002; Rosenkranz et al. 2003). Previous research has shown that electrical stimulation of the PL, when paired with a conditioned tone, does not significantly alter freezing at the time of stimulation, but impairs extinction recall on the following day (Vidal-Gonzalez et al. 2006). Therefore, we expected PL-Ptx to increase the expression of fear. However, the important point is that the extinction enhancements on the following days are specific to IL activation; PL activation does not accelerate extinction. The absence of a PL-Ptx enhancement on extinction might be explained by the lack of PL input to ITC cells.

It seems necessary to briefly address the point that acute PL-Ptx did reduce freezing in a conditioned context. Several explanations may account for the reduction in freezing by
PL-Ptx. For example, electrical stimulation of the PL reduces the increase in blood pressure and tachycardia evoked by amygdala stimulation, suggesting that the PL may play an inhibitory role in response to amygdala activation. Alternatively, the reduction of freezing may be a nonspecific effect of Ptx-activation produced by PL projections outside of the amygdala. Canales (2005) reported that intra-PL-Ptx induced c-Fos in motor areas such as the caudate-putamen. Accordingly, PL stimulation increased stereotypical behaviors such as head-down sniffing and upper body tics. It is possible that the PL-Ptx attenuation of freezing that we report may reflect PL activation of motor circuits and the induction of stereotypical movements that mask the expression of conditioned fear as measured by freezing (al Maskati and Zbrozyna 1989). Thus, explanation for the attenuation of freezing by acute PL-Ptx is unclear.

In concluding, it can be noted that that there is an emerging human literature linking mPFC activity to the regulation of fear (Phelps et al. 2004; Rauch et al. 2006; Milad et al. 2007; Delgado et al. 2008), and the dysregulation of the mPFC to anxiety disorders (for review, see Shin and Liberzon 2010). Amygdala hyperactivity in these disorders is often accompanied by mPFC hypoactivity or reduced mPFC volume (Drevets 1999; Shin et al. 2006; Berkowitz et al. 2007), and it has been suggested that successful treatment of these disorders involves increases in PFC function (DeRubeis et al. 2008; Fales et al. 2009). The present studies suggest that under certain conditions, artificial IL activation during the experience of fear may enhance the inhibition of fear and strengthen IL connectivity to fear-regulating areas. This sort of process could have profound impact on the expression of fear and dampen the consequences of future fearful experiences.

\section{Materials and Methods}

\section{Subjects}

Adult male Sprague-Dawley rats (325-350 g; Harlan) were used in all experiments. Upon arrival, rats were housed in pairs for $7 \mathrm{~d}$ before receiving surgery; following surgery, rats were singly housed. The colony room was maintained on a 12:12-h light:dark cycle (on at $0700 \mathrm{~h}$ ) with ad libitum access to standard lab chow and water. The University of Colorado Animal Care and Use Committee approved all protocols.

\section{Cannulations and histology}

Surgery was carried out under anesthesia with either inhalational isofluorane or halothane. Bilateral microinjection cannulae (26 g, $1 \mathrm{~mm}$ center-to-center; Plastics One) were implanted. With the exception of Experiment 5, cannulae were lowered to the IL (2.8 $\mathrm{AP}, 3.6 \mathrm{DV}, \pm 0.5 \mathrm{LM})$. For Experiment 5 , the tips of the cannulae terminated in the PL (3.2 AP, $1.8 \mathrm{DV}, \pm 0.5 \mathrm{LM})$. Coordinates were taken from bregma and dura according to Paxinos and Watson (1998). A stylet extending $1 \mathrm{~mm}$ beyond the guide cannula tip was inserted. Rats were allowed $10-14 \mathrm{~d}$ to recover in their home cages before behavioral testing began.

At the termination of each experiment, rats were injected bilaterally with $0.25 \mu \mathrm{L}$ of $10 \%$ Evans Blue solution to mark cannulae placement. Each cannula location was verified from $35-\mu \mathrm{m}$ sections stained with cresyl violet. Only rats with injection sites within the area of interest were included in analysis.

\section{Microinjections}

Rats were injected bilaterally with $0.25 \mu \mathrm{L}$ of $62.5 \mathrm{ng} /$ side Ptx (Sigma) in $0.9 \%$ sterile saline or saline alone. The rats were gently restrained in a towel while a dual microinjector $(33 \mathrm{~g}$, Plastics One) was inserted through the cannula extending $1 \mathrm{~mm}$ past the cannula tip. The injector was connected with PE 50 tubing to a $25-\mu$ L Hamilton syringe and a Kopf microinjection unit (Model 5000 ). The volume was injected over a period of $30 \mathrm{sec}$ and the injector was left in place for 2 min to allow diffusion. 


\section{Conditioning apparatus}

In all experiments, freezing was defined as the absence of all movement apart from respiration. Using a sampling procedure, each rat was scored every $10 \mathrm{sec}$ as either freezing or not freezing. The experimenter was blind to treatment condition.

\section{Context $A$}

Conditioning for all experiments, unless indicated, occurred in one of two clear Plexiglas boxes $(26 \mathrm{~cm} \mathrm{~L} \times 21 \mathrm{~cm} \mathrm{~W} \times 24 \mathrm{~cm} \mathrm{H})$ placed inside Igloo coolers with white interiors, small fans, and a 24-V DC clear light. The Plexiglas boxes sat on top of a shock grid (steel rods 1.5 -mm diameter, spaced $1.2 \mathrm{~mm}$ center-to-center; Model E10-30SR, Coulbourn Instruments). Each grid was wired to a shock generator and scrambler (Model H13-16, Coulbourn Instruments) for the delivery of footshock unconditioned stimulus (US). Each shock lasted 2 sec. The rods and floor were cleaned with $70 \%$ ethanol between animals. This context was designated as Context A for Experiments 3 and 4.

\section{Context B}

When indicated (Experiments 3 and 4), conditioning in Context B occurred in one of two clear Plexiglas bowls $(40-\mathrm{cm}$ diameter and $31-\mathrm{cm}$ deep) with $3-\mathrm{cm}$ bedding. The room was lit with a $120-\mathrm{V}$ red bulb. In Experiment 4, rats did not receive shock but were simply placed in the context. In Experiment 3, each rat was gently restrained while two copper electrodes $(0.5 \mathrm{~cm})$ were attached to the base of each rat's tail with tape. Alligator clips and $1 \mathrm{~m}$ of wire connected the electrodes to a shock generator and scrambler (Model H13-16, Coulbourn Instruments) for the administration of tail shock US. Each shock was $1.0 \mathrm{~mA}$ intensity and lasted 2 sec. The bowls were cleaned with $10 \%$ quatracide and bedding was replaced between animals. For testing trials, electrodes were taped to each rat's tail before placing in Context B.

\section{Procedures for specific experiments}

\section{Experiment 1. Does IL activation in a fear context potentiate subsequent fear extinction?}

On Day 0, each rat was placed in the conditioning chamber and allowed to explore for $2 \mathrm{~min}$. Five 1.0-mA footshocks ( $1 \mathrm{~min}$ intertrial interval [ITI]) were delivered and rats were immediately removed and returned to their home cage. On Day 1 , rats received IL-Ptx or saline $45 \mathrm{~min}$ before being placed in the conditioning chamber where freezing was scored for 5 min. On Days 2-4 rats were tested for freezing in the conditioning context for 5 min each day.

\section{Experiment 2. Would facilitated extinction learning emerge on the first extinction day after IL activation in a fear context if the extinction session was longer?}

On Day 0, each rat was placed in the conditioning context and allowed to explore for $2 \mathrm{~min}$ before receiving five $1.0-\mathrm{mA}$ tail shocks (1 min ITI). On Day 1, rats received IL-Ptx or Sal 45 min before being placed in the conditioning chamber and freezing was scored for $5 \mathrm{~min}$. On Day 2, rats were placed in the conditioning chamber for $20 \mathrm{~min}$ and freezing was scored. Data on Day 2 was analyzed in 5-min segments.

\section{Experiment 3. Do the effects of IL activation in a fear context on extinction transcend fear contexts?}

On Day 0, each rat was placed in Context A and allowed to explore for $2 \mathrm{~min}$. Two 1.0-mA footshocks (1 min ITI) were delivered and rats were returned to their home cage. Approximately $6 \mathrm{~h}$ later, each rat was placed in Context $\mathrm{B}$ and allowed to explore for 2 min before receiving two 1.0-mA tailshocks. On Day 1, rats received IL-Ptx or Sal 45 min before being tested for freezing in either Context A or Context B for 5 min. On Days 2-7, rats were tested 5 min for freezing in the opposite context from the one in which they had received the injection on Day 1 . The contexts were counterbalanced across drug treatment groups. On Days $8-10$, rats were placed for $5 \mathrm{~min}$ in the initial context in which they had received the injection on Day 1. Due to experimental constraints of time and cannulae integrity, only one cohort of animals out of the two were tested on Days 8-9, and some days are missing data points (Sal $n=9$, Ptx $n=8$ ).

\section{Experiment 4. Does IL activation have to occur in a fear context to enhance subsequent extinction?}

On Day 0 each rat was placed in Context $\mathrm{B}$ and allowed to explore for $5 \mathrm{~min}$. Approximately $4 \mathrm{~h}$ later, each rat was placed in Context A, and five 1.0-mA footshocks (1 min ITI) were delivered. On Day 1 , rats received IL-Ptx or Sal $45 \mathrm{~min}$ before being placed in either Context A or Context B where freezing was scored for $5 \mathrm{~min}$. On Days 2-4 each rat was placed in Context A (fear context) for 5 min a day and freezing was scored. This resulted in a 2 (drug) $\times$ 2 (context on day 1 ) design.

\section{Experiment 5. Is facilitation of later extinction specific to IL activation?}

On Day 0, each rat was placed in the conditioning chamber and received five 1.0-mA footshocks (1 min ITI). On Day 1, rats received intra-PL-Ptx or Sal 45 min before being placed in the conditioning chamber where freezing was scored for $5 \mathrm{~min}$. On Days 2-8 rats were tested for freezing in the conditioned context 5 min each day.

\section{Experiment 6. Is the facilitation of fear extinction produced by IL activation in} a fear context temporally limited?

On Day 0, each rat was placed in the conditioning context and allowed to explore for $2 \mathrm{~min}$ before receiving five $1.0-\mathrm{mA}$ footshocks (1 min ITI). On Day 1, rats received IL-Ptx or Sal $45 \mathrm{~min}$ before being placed in the conditioned context for 5 min where freezing was scored. For the following $6 \mathrm{~d}$ (Days $2-7)$ rats remained in their home cage. On Days $8-10$, rats were placed in the conditioned context for $5 \mathrm{~min}$ and freezing was scored.

\section{Acknowledgments}

This research was supported by National Institutes of Health Grant MH050479.

\section{References}

Abraham WC. 1999. Metaplasticity: Key element in memory and learning? News Physiol Sci 14: 85

Abraham WC. 2008. Metaplasticity: Tuning synapses and networks for plasticity. Nat Rev Neurosci 9: 387. doi: 10.1038/nrn2356.

Abraham WC, Bear MF. 1996. Metaplasticity: The plasticity of plasticity. Trends Neurosci 4: 126-130.

al Maskati HA, Zbrozyna AW. 1989. Stimulation in prefrontal cortex area inhibits cardiovascular and motor components of the defence reaction in rats. J Auton Nerv Syst 28: 117-125.

Amano T, Unal CT, Paré D. 2010. Synaptic correlates of fear extinction in the amygdala. Nat Neurosci 13: 489-494.

Amat J, Baratta MV, Paul E, Bland ST, Watkins LR, Maier SF. 2005. Medial prefrontal cortex determines how stressor controllability affects behavior and dorsal raphe nucleus. Nat Neurosci 8: $365-371$.

Amat J, Paul E, Zarza C, Watkins LR, Maier SF. 2006. Previous experience with behavioral control over stress blocks the behavioral and dorsal raphe nucleus activating effects of later uncontrollable stress: Role of the ventral medial prefrontal cortex. J Neurosci 26: $13264-13272$.

Amat J, Paul E, Watkins LR, Maier SF. 2008. Activation of the ventral medial prefrontal cortex during an uncontrollable stressor reproduces both the immediate and long-term protective effects of behavioral control. Neuroscience 154: 1178-1186. 
Baratta MV, Christianson JP, Gomez DM, Zarza CM, Amat J, Masini CV, Watkins LR, Maier SF. 2007. Controllable versus uncontrollable stressors bi-directionally modulate conditioned but not innate fear. Neuroscience 146: 1495-1503.

Baratta MV, Lucero TR, Amat J, Watkins LR, Maier SF. 2008. Role of the ventral medial prefrontal cortex in mediating behavioral control-induced reduction of later conditioned fear. Learn Mem 15: $84-87$.

Baratta MV, Zarza CM, Gomez DM, Campeau S, Watkins LR, Maier SF. 2009. Selective activation of dorsal raphe nucleus-projecting neurons in the ventral medial prefrontal cortex by controllable stress. Eur J Neurosci 30: $1111-1116$.

Berkowitz RL, Coplan JD, Reddy DP, Gorman JM. 2007. The human dimension: How the prefrontal cortex modulates the subcortical fear response. Rev Neurosci 18: 191-207.

Berretta S, Pantazopoulos H, Caldera M, Pantazopoulos P, Paré D. 2005. Infralimbic cortex activation increases c-Fos expression in intercalated neurons of the amygdala. Neuroscience 132: 943-953.

Bouton ME. 2004. Context and behavioral processes in extinction. Learn Mem 11: 485-494.

Bredy TW, Wu H, Crego C, Zellhoefer J, Sun YE, Barad M. 2007. Histone modifications around individual BDNF gene promoters in prefrontal cortex are associated with extinction of conditioned fear. Learn Mem 14: $268-276$.

Brinley-Reed M, Mascagni F, McDonald AJ. 1995. Synaptology of prefrontal cortical projections to the basolateral amygdala: An electron microscopic study in the rat. Neurosci Lett 202: 45-48.

Burgos-Robles A, Vidal-Gonzalez I, Santini E, Quirk GJ. 2007. Consolidation of fear extinction requires NMDA receptor-dependent bursting in the ventromedial prefrontal cortex. Neuron 53: 871-880.

Canales JJ. 2005. Intermittent cortical stimulation evokes sensitization to cocaine and enduring changes in matrix and striosome neuron responsiveness. Synapse 57: 56-60.

Cassell MD, Wright DJ. 1986. Topography of projections from the medial prefrontal cortex to the amygdala in the rat. Brain Res Bull 17: 321-333.

Chagnac-Amitai Y, Connors BW. 1989. Horizontal spread of synchronized activity in neocortex and its control by GABA-mediated inhibition. J Neurophysiol 61: 747-775.

Chang CH, Maren S. 2010. Strain difference in the effect of infralimbic cortex lesions on fear extinction in rats. Behav Neurosci 124: $391-397$.

Delgado MR, Nearing KI, Ledoux JE, Phelps EA. 2008. Neural circuitry underlying the regulation of conditioned fear and its relation to extinction. Neuron 59: 829-838.

DeRubeis RJ, Siegle GJ, Hollon SD. 2008. Cognitive therapy versus medication for depression: Treatment outcomes and neural mechanisms. Nat Rev Neurosci 9: 788-796.

Drevets WC. 1999. Prefrontal cortical-amygdalar metabolism in major depression. Ann N Y Acad Sci 877: 614-637.

Ehrlich I, Humeau Y, Grenier F, Ciocchi S, Herry C, Lüthi A. 2009. Amygdala inhibitory circuits and the control of fear memory. Neuron 62: $757-771$.

Fales CL, Barch DM, Rundle MM, Mintun MA, Mathews J, Snyder AZ, Sheline YI. 2009. Antidepressant treatment normalizes hypoactivity in dorsolateral prefrontal cortex during emotional interference processing in major depression. I Affect Disord 112: 206-211.

Feenstra MG, Vogel M, Botterblom MH, Joosten RN, de Bruin JP. 2001. Dopamine and noradrenaline efflux in the rat prefrontal cortex after classical aversive conditioning to an auditory cue. Eur J Neurosci 13: $1051-1054$

Fendt M, Fanselow MS. 1999. The neuroanatomical and neurochemical basis of conditioned fear. Neurosci Biobehav Rev 23: 743-760.

Gabbott PLA, Warner TA, Jays PRL, Salway P, Busby SJ. 2005. Prefrontal cortex in the rat: Projections to subcortical autonomic, motor, and limbic centers. J Comp Neurol 492: 145-177.

Gonzalez-Lima F, Bruchey AK. 2004. Extinction memory improvement by the metabolic enhancer methylene blue. Learn Mem 11: 633-640.

Gu Q. 2002. Neuromodulatory transmitter systems in the cortex and their role in cortical plasticity. Neuroscience 111: 815-835.

Herry C, Mons N. 2004. Resistance to extinction is associated with impaired immediate early gene induction in medial prefrontal cortex and amygdala. Eur J Neurosci 20: 781-790.

Herry C, Ciocchi S, Senn V, Demmou L, Müller C, Lüthi A. 2008. Switching on and off fear by distinct neuronal circuits. Nature 454: 600-606.

Hugues S, Deschaux O, Garcia R. 2004. Postextinction infusion of a mitogen-activated protein kinase inhibitor into the medial prefrontal cortex impairs memory of the extinction of conditioned fear. Learn Mem 11: 540-543.

Hugues S, Garcia R, Léna I. 2007. Time course of extracellular catecholamine and glutamate levels in the rat medial prefrontal cortex during and after extinction of conditioned fear. Synapse 61: 933-937.

Kim C, Jo YS, Kim IH, Choi JS. 2010. Lack of medial prefrontal cortex activation underlies the immediate extinction deficit. J Neurosci 30: 832-837.

Knapska E, Maren S. 2009. Reciprocal patterns of c-Fos expression in the medial prefrontal cortex and amygdala after extinction and renewal of conditioned fear. Learn Mem 16: 486-493.

Laurent V, Westbrook RF. 2008. Distinct contributions of the basolateral amygdala and the medial prefrontal cortex to learning and relearning extinction of context conditioned fear. Learn Mem 15: 657-666.

Laurent V, Westbrook RF. 2009. Inactivation of the infralimbic but not the prelimbic cortex impairs consolidation and retrieval of fear extinction. Learn Mem 16: 520-529.

Laurent V, Marchand AR, Westbrook RF. 2008. The basolateral amygdala is necessary for learning but not relearning extinction of context conditioned fear. Learn Mem 15: 304-314.

Likhtik E, Pelletier JG, Paz R, Paré D. 2005. Prefrontal control of the amygdala. J Neurosci 25: 7429-7437.

Likhtik E, Popa D, Apergis-Schoute J, Fidacaro GA, Paré D. 2008. Amygdala intercalated neurons are required for expression of fear extinction. Nature 454: 642-645.

Maier SF, Amat J, Baratta MV, Paul E, Watkins LR. 2006. Behavioral control, the medial prefrontal cortex, and resilience. Dialogues Clin Neurosci 8: 397-406.

Mamiya N, Fukushima H, Suzuki A, Matsuyama Z, Homma S, Frankland PW, Kida S. 2009. Brain region-specific gene expression activation required for reconsolidation and extinction of contextual fear memory. I Neurosci 29: 402-413.

Maren S, Quirk GJ. 2004. Neuronal signalling of fear memory. Nat Rev Neurosci 5: 844-852.

McDonald AJ, Mascagni F, Guo L. 1996. Projections of the medial and lateral prefrontal cortices to the amygdala: A Phaseolus vulgaris leucoagglutinin study in the rat. Neuroscience 71: 55-75.

Milad MR, Quirk GJ. 2002. Neurons in medial prefrontal cortex signal memory for fear extinction. Nature 420: 70-74.

Milad MR, Vidal-Gonzalez I, Quirk GJ. 2004. Electrical stimulation of medial prefrontal cortex reduces conditioned fear in a temporally specific manner. Behav Neurosci 118: 389-394.

Milad MR, Wright CI, Orr SP, Pitman RK, Quirk GJ, Rauch SL. 2007. Recall of fear extinction in humans activates the ventromedial prefrontal cortex and hippocampus in concert. Biol Psychiatry 62: 446-454.

Mueller D, Porter JT, Quirk GJ. 2008. Noradrenergic signaling in infralimbic cortex increases cell excitability and strengthens memory for extinction. J Neurosci 28: $369-375$.

Myers KM, Davis M. 2007. Mechanisms of fear extinction. Mol Psychiatry 12: $120-150$

Paré D, Royer S, Smith Y, Lang EJ. 2003. Contextual inhibitory gating of impulse traffic in the intra-amygdaloid network. Ann N Y Acad Sci 985: 78-91.

Paré D, Quirk GJ, Ledoux JE. 2004. New vistas on amygdala networks in conditioned fear. J Neurophysiol 92: 1-9.

Paxinos G, Watson C. 1998. The rat brain in stereotaxic coordinates, 4th ed. Academic Press, New York.

Peters J, Dieppa-Perea LM, Melendez LM, Quirk GJ. 2010. Induction of fear extinction with hippocampal-infralimbic BDNF. Science 328: $1288-1290$.

Phelps EA, Delgado MR, Nearing KI, LeDoux JE. 2004. Extinction learning in humans: Role of the amygdala and vmPFC. Neuron 43: 897-905.

Pinto A, Sesack SR. 2008. Ultrastructural analysis of prefrontal cortical inputs to the rat amygdala: Spatial relationships to presumed dopamine axons and D1 and D2 receptors. Brain Struct Funct 213: $159-175$.

Quirk GJ, Likhtik E, Pelletier JG, Paré D. 2003. Stimulation of medial prefrontal cortex decreases the responsiveness of central amygdala output neurons. J Neurosci 23: 8800-8807.

Rauch SL, Shin LM, Phelps EA. 2006. Neurocircuitry models of posttraumatic stress disorder and extinction: Human neuroimaging research — past, present, and future. Biol Psychiatry 60: 376-382.

Rosenkranz JA, Grace AA. 2001. Dopamine attenuates prefrontal cortical suppression of sensory inputs to the basolateral amygdala of rats. J Neurosci 21: 4090-4103.

Rosenkranz JA, Grace AA. 2002. Cellular mechanisms of infralimbic and prelimbic prefrontal cortical inhibition and dopaminergic modulation of basolateral amygdala neurons in vivo. J Neurosci 22: 324-337.

Rosenkranz JA, Moore H, Grace AA. 2003. The prefrontal cortex regulates lateral amygdala neuronal plasticity and responses to previously conditioned stimuli. J Neurosci 23: 11054-11064.

Royer S, Paré D. 2002. Bidirectional synaptic plasticity in intercalated amygdala neurons and the extinction of conditioned fear responses. Neuroscience 115: 455-462. 
Royer S, Martina M, Paré D. 1999. An inhibitory interface gates impulse traffic between the input and output stations of the amygdala. J Neurosci 19: 10575-10583.

Santini E, Ge H, Ren K, Peña de Ortiz S, Quirk GJ. 2004. Consolidation of fear extinction requires protein synthesis in the medial prefrontal cortex. J Neurosci 24: 5704-5710.

Santini E, Quirk GJ, Porter JT. 2008. Fear conditioning and extinction differentially modify the intrinsic excitability of infralimbic neurons. J Neurosci 28: 4028-4036.

Shin LM, Liberzon I. 2010. The neurocircuitry of fear, stress, and anxiety disorders. Neuropsychopharmacology 35: 169-191.

Shin LM, Rauch SL, Pitman RK. 2006. Amygdala, medial prefrontal cortex, and hippocampal function in PTSD. Ann N Y Acad Sci 1071: 67-79.

Smith Y, Paré JF, Paré D. 2000. Differential innervation of parvalbumin-immunoreactive interneurons of the basolateral amygdaloid complex by cortical and intrinsic inputs. J Comp Neurol 416: $496-508$.
Sotres-Bayon F, Diaz-Mataix L, Bush DE, LeDoux JE. 2009. Dissociable roles for the ventromedial prefrontal cortex and amygdala in fear extinction: NR2B contribution. Cereb Cortex 19: 474-482.

Vertes RP. 2004. Differential projections of the infralimbic and prelimbic cortex in the rat. Synapse 51: $32-58$.

Vidal-Gonzalez I, Vidal-Gonzalez B, Rauch SL, Quirk GJ. 2006. Microstimulation reveals opposing influences of prelimbic and infralimbic cortex on the expression of conditioned fear. Learn Mem 13: $728-733$.

Wedzony K, Maćkowiak M, Fijał K, Gołembiowska K. 1996. Evidence that conditioned stress enhances outflow of dopamine in rat prefrontal cortex: A search for the influence of diazepam and 5-HT1A agonists. Synapse 24: 240-247.

Received June 28, 2010; accepted in revised form August 26, 2010. 


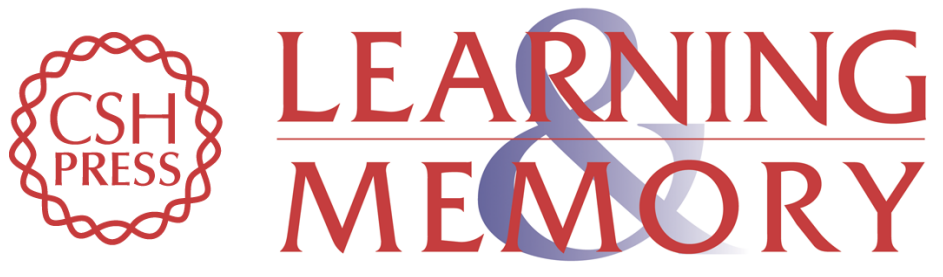

\section{Activation of the infralimbic cortex in a fear context enhances extinction learning}

Brittany M. Thompson, Michael V. Baratta, Joseph C. Biedenkapp, et al.

Learn. Mem. 2010, 17:

Access the most recent version at doi:10.1101//m.1920810

References This article cites 72 articles, 23 of which can be accessed free at: http://learnmem.cshlp.org/content/17/11/591.full.html\#ref-list-1

License

Email Alerting

Receive free email alerts when new articles cite this article - sign up in the box at the Service top right corner of the article or click here. 